\title{
Orphan nuclear receptors-new ligands and new possibilities
}

\author{
Bruce Blumberg ${ }^{1,3,4}$ and Ronald M. Evans ${ }^{1,2,4}$ \\ ${ }^{1}$ Gene Expression Laboratory, ${ }^{2}$ Howard Hughes Medical Institute, The Salk Institute for Biological Studies, La Jolla, \\ California 92037 USA
}

Nuclear hormone receptors comprise a large superfamily of ligand-modulated transcription factors that, in part, mediate response to steroids, retinoids and thyroid hormones and play key roles in development and body physiology (for review, see Beato et al. 1995; Kastner et al. 1995; Mangelsdorf and Evans 1995; Mangelsdorf et al. 1995; Enmark and Gustaffson 1996; Willy and Mangelsdorf 1998). Ten years ago the first orphan nuclear receptors were isolated, raising the first portents toward a new era in physiology (Giguere et al. 1988). Although structurally related to the known receptors, no physiological ligands or activators were known for these orphan receptors which are more numerous (19 families) than receptors with known ligands (10 families). Orphan receptors represent a diverse and ancient component of the nuclear receptor superfamily, being found in nearly all animal species examined. Orphan nuclear receptors provide a unique and, until recently, largely untapped resource to uncover regulatory systems that impact on both health and human disease. Shortly after their isolation, strategies were devised to identify orphan ligands using the receptor as a screening target. This process, referred to as 'reverse endocrinology,' has led previously to the identification of ligands for RXRs [9-cis retinoic acid receptors (RARs), a.k.a. retinoid $\underline{X}$ receptors], PPARs (peroxisome proliferator-activated receptors), FXRs (ㅁarnesoid $\underline{X}$ receptors), and LXRs (liver $\underline{X}$ receptors).

In a review eight years ago, Bert $\mathrm{O}^{\prime}$ Malley predicted that the field of orphan receptors would provide much excitement for the future (O'Malley 1990). The promise of orphan receptors is that they provide an opportunity to identify not only novel ligands but perhaps unsuspected classes of ligands and potentially new principles of physiology. Because all known receptors are important in the treatment of human disease, their signaling pathways have direct implications for drug discovery. The purpose of this review is to highlight advances made on four new orphan receptor-mediated signaling pathways [BXR (benzoate $\underline{X}$ receptor), CAR $\beta$ (constitutive an-

\footnotetext{
${ }^{3}$ Present address: Department of Developmental and Cell Biology, University of California, Irvine, California 92697-2300 USA.

${ }^{4}$ Corresponding authors.

E-MAIL blumberg@axp1.salk.edu; evans@salk.edu; FAX (619) 455-1349.
}

drostane receptor), PXR (pregnane $\underline{X}$ receptor), and SXR [steroid and Xenobiotic receptor)] with brief updates on recent progress for FXR, PPAR $\gamma$, and LXR $\alpha$. To restrict the scope of the review, we will focus only on orphans forming heterodimers with RXR and studies that have been reported in the last year. We will emphasize what has been learned about the nature of the ligands, new modes of regulation, insights into physiology, and potential new drug targets.

\section{RXR heterodimers and ligand dependence}

Although inherently promising, not all orphans (and perhaps only a few) can be expected to represent unidentified endocrine systems. Therefore, a central and critical problem is identifying which of the many orphan receptors are good candidates to be ligand responsive. An interesting feature of the known, nonsteroidal ligand-activated nuclear receptors is that they all require heterodimerization with RXR, for high-affinity DNA binding. We and others speculated that RXR heterodimerization might be a signature feature for one class of ligand-responsive receptors. Indeed, with the identification of BXR, SXR, PXR, and CAR $\beta$, all nuclear receptors now known to require heterodimerization with RXR for DNA-binding are ligand-responsive (Fig. 1). Thus, RXR is a common partner in at least 11 distinct signaling pathways. The activation state of RXR varies among these heterodimers, adding to the complexity and potential diversity of hormonal signaling. RXR can be completely silent in nonpermissive heterodimers with the thyroid hormone receptor (TR) or the vitamin D receptor (VDR) (Kurokawa et al. 1994; Forman et al. 1995a) although it is freely activatable in permissive heterodimers with PPAR (Kliewer et al. 1992b), LXR $\alpha$ (Willy et al. 1995), and FXR/RIP14 (Forman et al. 1995b; Zavacki et al. 1997). In the case of the RAR heterodimer, RXR can be activated only after the addition of an RAR ligand (Forman et al. 1995a; Schulman et al. 1997). The ability of RXR to be activated in other heterodimers has not been reported. The activation state of RXR in a particular heterodimer can have important consequences for treating disease. For example, in animal models for 

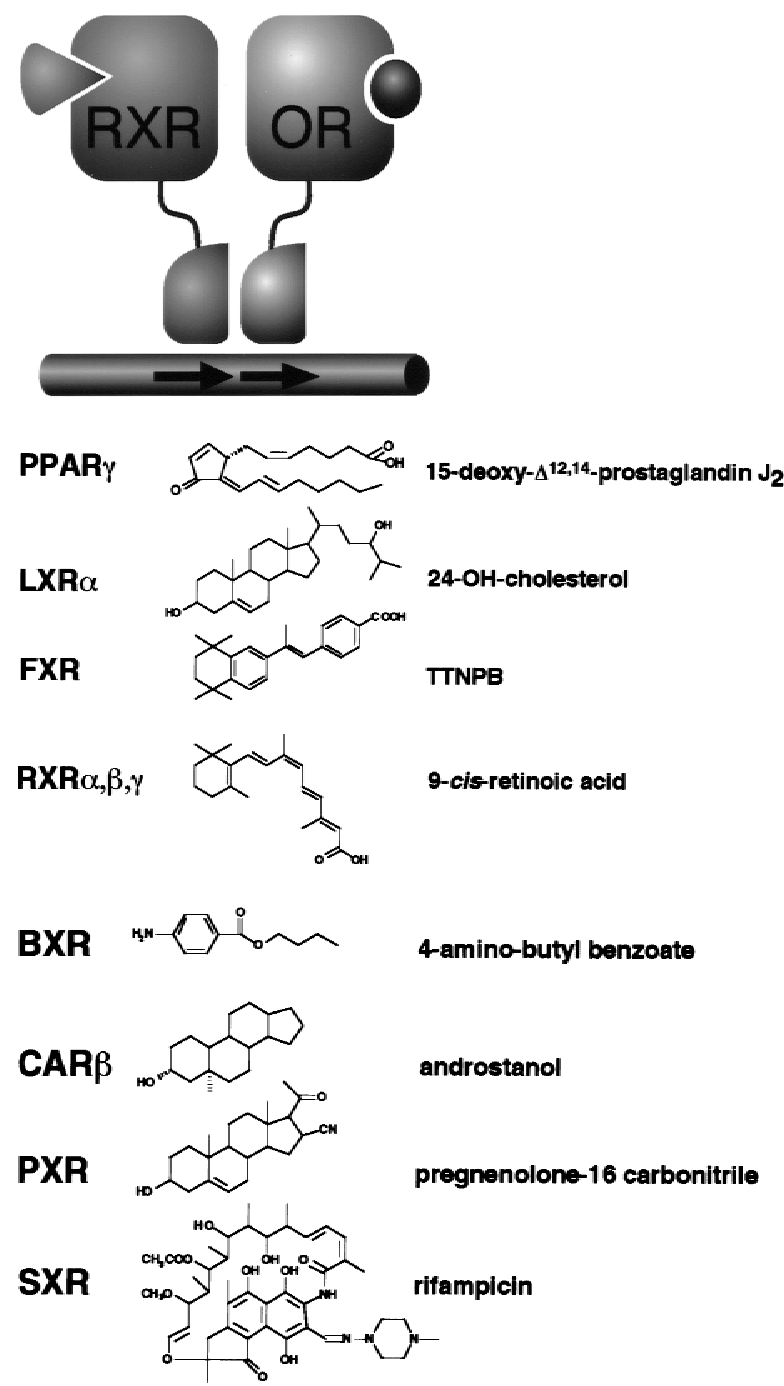

Figure 1. Schematic illustration of RXR heterodimerizing with an orphan receptor. RXR typically occupies the $5^{\prime}$ half-site in the response element. Representative natural ligands are shown next to the corresponding receptor. Synthetic activators are shown where endogenous ligands are not known.

noninsulin-dependent diabetes mellitus (NIDDM) the addition of RXR-selective ligands can potentiate the effects of known antidiabetic PPAR $\gamma$ activators and sensitize animals to insulin (Mukherjee et al. 1997). This RXR-targeted therapy is now in clinical trials.

\section{Four new orphan receptor signaling pathways}

Sequence analysis shows that the four newly described ligand-dependent receptors (BXR, CAR $\beta$, PXR, and SXR) are closely related to each other and they appear to comprise a distinct branch of the family tree. Therefore, one might expect them to share some common properties. Each requires heterodimerization with RXR for high-affinity DNA binding. The preferred organization of the hormone response element is as direct repeats (DR) of AGTTCA (rather than the canonical AGGTCA) separated by four (DR-4, BXR, PXR, SXR) or five nucleotides (DR-5, CAR). PXR, SXR, and CAR are highly expressed in the liver and respond to steroidal ligands. Together, they are the first new steroid-responsive nuclear receptors described since the isolation of the mineralocorticoid receptor in 1987 and the first new steroidal ligands since aldosterone in 1952.

\section{$C A R \beta$ - a ligand inactivated receptor}

All of the ligand-dependent nuclear receptors described to date are activated by a ligand-induced association with coactivator proteins. Recent studies with CAR $\beta$ appear to reverse this paradigm (Forman et al. 1998). When isolated, CAR $\beta$ was found to be constitutively active on candidate DR-5 response elements. This could be the result of the production of an endogenous intracellular ligand or inherent activity in an unliganded state. Because CAR $\beta$ is also active in yeast, production of an endogenous ligand seemed unlikely. Thus, although lacking precedent, a ligand screen was established that would register an increase or a decrease in CAR $\beta$ activity. This resulted in the identification of androstanol and androstenol as surprising but selective transcriptional inhibitors (Forman et al. 1998). These androgens completely lack activity on the androgen receptor whereas classic androgens such as testosterone fail to act on CAR $\beta$. How the ligand reverses activation by inducing coactivator release, rather than recruitment, remains a structural conundrum and a solution will likely require a combination of mutational studies and crystal structure in the presence and absence of ligand. Although CAR $\beta$-specific androstanes are related to mammalian pheromones, the CAR $\beta$ expression pattern makes it unlikely to participate in this process. Rather, this work suggests a completely new area of androgen physiology that will require knockouts and synthetic ligands to tease out its relevance.

\section{$B X R$ - an embryonic benzoate receptor}

The specification of positional information and the transfer of patterning signals are key events during early embryogenesis. One class of information transfer is mediated by diffusible substances called morphogens, some of which, like retinoic acid, are small lipophilic molecules. We hypothesized that additional related developmental signaling systems might exist and thus searched for novel embryonic orphan receptors, with the hope that one or more of these might be ligand dependent (Blumberg et al. 1992). One of these receptors, BXR (previously called ONR-1; Smith et al. 1994a), was identified as an obligate RXR heterodimeric partner, both in vitro and in vivo, establishing it as a candidate for a ligand screen (Blumberg et al. 1998a). BXR mRNA is expressed during early development suggesting embryos as a likely ligand source. HPLC fractionation of embryonic ex- 
tracts, guided by the ability of fractions to stimulate BXR target genes, revealed several activity peaks. Scale-up purification followed by mass spectrometry and ${ }^{1} \mathrm{H}-\mathrm{NMR}$ analysis identified alkyl esters of amino and hydroxy benzoic acids as potent, stereoselective activators. In vitro binding experiments verified that these were bona fide receptor ligands (Blumberg et al. 1998a). Benzoates comprise a new molecular class of nuclear receptor ligand and their activity suggests that BXR may control a previously unsuspected vertebrate signaling pathway. This identification of BXR and its benzoate ligands by using an orphan receptor as a probe to identify the corresponding endogenous ligand in a totally bioassayguided screen suggests that such an approach may be fruitful in identifying endogenous ligands for other receptors.

The identification of nuclear receptors and their ligands in the pre-gastrula embryo, long before any organs have formed, suggests that the classic endocrine paradigm is not operative in early development. Instead, it appears that the ligands either diffuse from their point of origin to neighboring cells (paracrine signaling) or perhaps act within the cells where they are synthesized (autocrine signaling). The endogenous benzoate activators are structurally related to the nutrient p-amino benzoic acid, a precursor to folic acid, suggesting a potential connection between nutrition and development.

\section{PXR-pregnane-activated receptor}

The appearance in the GenBank database of a mouse EST encoding an apparently novel member of the nuclear receptor superfamily led a group at GlaxoWellcome Pharmaceuticals to clone the full-length receptor cDNA and screen it against a panel of known compounds to identify potential activators (Kliewer et al. 1998). This receptor was transcriptionally activated by synthetic steroids and steroid antagonists and termed PXR based on its activation by synthetic C21 steroids. An interesting feature of PXR biology is its ability to respond to both steroid receptor agonists and antagonists. Such behavior is uncharacteristic of the classic steroid receptors such as glucocorticoid receptor (GR) and establishes PXR as an atypical mediator of steroid action. The activators identified also provided an important clue to PXR target genes.

Hans Selye first introduced the concept that exogenous steroids and pharmacologic substances may function to modulate the expression of enzymes that would protect against subsequent exposure to toxic xenobiotic substances (Selye 1971). These 'catatoxic compounds' are typified by the synthetic glucocorticoid antagonist, pregnenolone-16-carbonitrile (PCN). Catatoxic compounds induce the proliferation of hepatic endoplasmic reticulum and the expression of cytochrome $\mathrm{P} 450$ genes which confer a nonspecific protection or immunity against numerous drugs and xenobiotic compounds, presumably by increasing their catabolism (Burger et al. 1992; Gonzalez et al. 1986).
A paradoxical feature of catatoxic compounds is that, whereas many of the most potent compounds (e.g., PCN, spironolactone, cyproterone acetate) are steroid receptor antagonists, others (e.g., dexamethasone) are receptor agonists (Burger et al. 1992). This argues that the induction of protection is independent of the known steroid receptors. Prominently inducible members of the rodent P450 3A gene family (CYP3A1, CYP3A2, CYP3A23) were shown previously to contain a DNA-response element that mediates this induction and the GlaxoWellcome group established this element as a PXR target. They showed that PXR can bind to and activate transcription through a multimerized CYP3A2 PCN and glucocorticoid-response element in response to potent CYP3A2 inducers such as PCN or dexamethasone (Kliewer et al. 1998). Thus, the response profile of PXR offers a possible answer to the paradoxical behavior of catatoxic compounds and the induction of CYP3A genes by steroids and steroid antagonists.

The activation of PXR by synthetic and natural C21 steroids has been interpreted to indicate that PXR is a high-affinity receptor for an, as yet, unidentified endogenous C21 steroid whose function is to coordinately regulate sterol and steroid metabolism (Kliewer et al. 1998). In this view, PXR induces the expression of genes such as CYP3A1, CYP3A2, CYP3A23, and perhaps cholesterol $7 \alpha$ hydroxylase in response to the pregnane $\mathrm{X}$. This is an interesting model that, if correct, suggests the existence of a unique and overlooked mediator of steroid metabolism. Proof of this model awaits the isolation of a bona fide, high-affinity, endogenous PXR ligand.

\section{SXR-a steroid and xenobiotic sensor}

A search for potential human BXR family members resulted in the identification of a new receptor termed SXR (Blumberg et al. 1998b). Although related to both BXR and PXR (73\% amino acid identity in the ligand binding domains between SXR and PXR, 43\% identity between SXR and BXR/ this receptor is pharmacologically distinct from both receptors. In contrast to PXR, the human receptor was shown to be activated by a diverse group of steroid agonists and antagonists including estranes, androstanes, and pregnanes (C18, C19, and C21 steroids, respectively). The response profile of SXR led to a novel model, 'the steroid sensor hypothesis,' which proposes that the detoxification and removal of various endogenous hormones, dietary steroids, drugs, and xenobiotic compounds with biological activity are regulated through the activation of a few broad-specificity sensing receptors rather than by numerous, specific receptors. Much of the detoxification and catabolism of such compounds is mediated by cytochrome $\mathrm{P} 450$ enzymes, particularly members of the CYP2A, CYP2B, CYP2C, CYP2D, CYP2E, and CYP3A families, most of which have broad substrate specificity and are inducible by a diversity of compounds, including steroids (Gonzalez 1992; Rendic and Di Carlo 1997). Hence it was proposed that SXR could directly regulate the activity of catabolic 
P450 enzymes in response to the presence of its substrates, providing a novel transcriptional pathway for direct regulation of metabolism (Blumberg et al. 1998b).

This hypothesis is supported by several important observations. (1) The sensor, SXR, is expressed at high levels in liver and intestine, both sites of steroid and xenobiotic metabolism. (2) SXR is activated by a variety of xenobiotics known to induce catabolic enzymes, such as rifampicin and nifedipine, steroid receptor agonists and antagonists, such as estrogen and tamoxifen, and bioactive dietary compounds, such as phytoestrogens (Blumberg et al. 1998b). (3) SXR-response elements are present in several genes encoding inducible cytochrome P450s and at least one, CYP3A4, is known to be activated by SXR in vitro (Blumberg et al. 1998b). CYP3A4, also known as testosterone-6-hydroxylase, metabolizes numerous steroids and xenobiotics, including $\sim 60 \%$ of clinically relevant drugs (Rendic and Di Carlo 1997) thus making it an ideal sensor target. (4) Activation of SXR should increase steroid catabolism. However, because steroid synthesis is tightly regulated, one might not expect to see altered plasma steroid levels when the sensor is stimulated by xenobiotic compounds leading to increased catabolism. Instead, increased catabolism should be compensated by the pituitary gland (in normal individuals) leading to ACTH release, increased steroid biosynthesis and, ultimately maintenance of plasma steroid levels but increased urinary levels of steroid metabolites. Interestingly, the current best SXR activator, rifampicin, is also known to be involved in numerous drug-drug interactions as a consequence of drastically altering their metabolism by inducing CYP3A4. Thus, long-term rifampicin therapy for tuberculosis also increases steroid clearance, in some cases leading to a misdiagnosis of Cushing's syndrome (Kyriazopoulou and Vagenakis 1992; Terzolo et al. 1995; Zawawi et al. 1996). In patients with Addison's disease, who are on steroid replacement therapy, or women taking oral contraceptives, rifampicin treatment leads to rapid depletion of administered steroids, confirming that induction of CYP3A4 causes increased steroid catabolism as predicted by the model (Edwards et al. 1974; Kyriazopoulou et al. 1984). Thus, SXR may play an important role in what has traditionally been a poorly understood aspect of drug pharmacology.

SXR and PXR are pharmacologically distinct in that strong activators of one receptor are typically weak activators of the other. For example, phytoestrogens, corticosterone, and rifampicin are potent SXR but poor PXR activators. In contrast, PCN and dexamethasone are strong PXR but poor SXR activators. However, both PXR and SXR appear to regulate the expression of CYP3A genes and are expressed highly where these catabolic enzymes are abundant. Hence, despite differences in pharmacology, the two receptors appear to act through a common metabolic pathway. Although it is possible that SXR has an unidentified, high-affinity ligand, this need not be the case if it is functioning as a sensor to trigger a broad-specificity detoxifying system. In this view, perhaps the structural and pharmacological differences be- tween SXR and PXR are more reflective of the differences in the diets of rodents and primates and the need to respond to a different set of ingested nutrients and xenobiotics.

\section{Old orphans grow up}

Identification of an orphan receptor, the demonstration that it is ligand dependent and characterization of agonistic or antagonistic ligands are indispensable first steps in understanding its biology. This information provides impetus for other laboratories to study these orphans which, in turn, leads to rapid advances in their biology. This section represents advances in the last year on FXR/ RIP14, PPAR $\gamma$, and LXR $\alpha$.

\section{FXR-a new type of retinoid receptor?}

FXR was first identified as a rat orphan receptor which could be activated by high concentrations of farnesol, an isoprene intermediate in the mevalonate biosynthetic pathway, presumably as the consequence of its conversion to an unidentified higher activity metabolite (Forman et al. 1995b). Interestingly, the mouse ortholog of FXR, RIP14, is only poorly activated by farnesoids but robustly by retinoic acid and the synthetic retinoid agonist TTNPB (Zavacki et al. 1997). FXR is also strongly activated by both RA and TTNPB (B. Forman, pers. comm.). Despite the potent response of FXR/RIP14 to retinoids, this activation requires supraphysiological concentrations of RA and it has been impossible to demonstrate direct binding of these compounds to the receptors, suggesting that they are unlikely to act as direct ligands. This raises the possibility that either an unidentified retinoid metabolite is the endogenous FXR/RIP14 ligand, or that both retinoids and farnesoids are mimicking the activity of an authentic ligand, perhaps another retinoid or terpenoid. Thus, FXR/RIP14 is either a seventh retinoid receptor or a novel terpenoid receptor, either of which is equivalently exciting. Knockouts and the use of FXR/RIP14 to probe for more potent and selective agonists and antagonists will significantly aid in exploring this signaling pathway.

\section{PPAR $\gamma$, cancer, inflammation, and atherosclerosis}

PPAR $\gamma$ serves as an excellent example of an orphan receptor in a more advanced stage of analysis (for a more detailed perspective, see Spiegelman 1998). Previous studies have identified the naturally occurring compound 15-deoxy prostaglandin J2 (PGJ2) and a the antidiabetic thiazolidinediones (TZDs) as PPAR $\gamma$ ligands (Forman et al. 1995c; Kliewer et al. 1995). PPAR $\gamma$ activation has been linked to adipocyte differentiation and the TZDs, such as troglitazone, are widely used in the treatment of adult onset (Type II) diabetes. In addition to adipose tissue (Chawla et al. 1994; Tontonoz et al. 1994) in the past year, PPAR $\gamma$ was found to be expressed in several additional cell types including mammary epithe- 
lia, colonic epithelia (Mueller et al. 1998), and two different classes of macrophages (Ricote et al. 1998; Jiang et al. 1998). In breast cancer and liposarcoma cell lines, PPAR $\gamma$ activators promote cell differentiation, suggesting a potential use of these compounds in the treatment of the associated diseases (Mueller et al. 1998). In resting macrophages, PPAR $y$ appears to block activation by phorbol esters and interferons, suggesting a potential anti-inflammatory effect (Jiang et al. 1998; Ricote et al. 1998).

Most recently, two novel and related PPAR $\gamma$ ligands were identified as a component of the lipid coat of oxidized low density lipoprotein (OX-LDL) (Nagy et al. 1998; Tontonoz et al. 1998). OX-LDL is known to contribute to atherogenic plaques and thus is an important component in the generation of coronary artery disease. The new ligands, 9- and 13-hydroxyoctadecadienoic acid (9- and 13-HODE) are oxidized derivatives of linoleic acid and are found abundantly in the monocytic foam cells that accumulate in fatty streaks of atherosclerotic lesions. As foam cells express PPAR $\gamma$, it was proposed that OX-LDL and its associated PPAR $\gamma$ ligands are internalized into foam cells by receptor-mediated endocytosis. Once inside the cell, the ligands are liberated, activating PPAR $\gamma$ that both contributes to foam cell formation and increases the expression of genes involved in receptor-mediated endocytosis (Nagy et al. 1998; Tontonoz et al. 1998). Thus, the identification of new ligands has rapidly led to new roles for PPAR $\gamma$ in cellular differentiation and human disease.

\section{LXR $\alpha$ and cholesterol biosynthesis}

The orphan receptor $\operatorname{LXR} \alpha$ was named by virtue of its enriched expression in the liver whereas LXR $\beta$ is expressed fairly ubiquitously. Recently, LXRs were shown to be activated by naturally-occurring oxidized cholesterol derivatives such as $22(\mathrm{R})$ and $24(\mathrm{~S})$ hydroxycholesterol and 24(S),25-epoxycholesterol (Janowski et al. 1996; Forman et al. 1997; Lehmann et al. 1997). This observation led to the proposition that LXR $\alpha$ could be involved in the regulation of cholesterol metabolism.

This model has received decisive support with the recent knockout of LXR $\alpha$ (Peet et al. 1998). Although LXR $\alpha^{-/-}$mice are viable and fertile, they lack the ability to catabolize dietary cholesterol leading to its accumulation in the liver with consequent hepatic failure. In knockout animals, bile acid synthesis is not upregulated and cholesterol uptake is not downregulated in response to increased dietary cholesterol, suggesting that the normal sensing mechanism is inoperative and implicating $\mathrm{LXR} \alpha$ as the sensor. In addition to defects in bile acid synthesis, the knockout animals also exhibit aberrant regulation of enzymes involved in cholesterogenesis and fatty acid synthesis. Fatty acid biosynthesis is downregulated in knockout animals, which suggests that LXR $\alpha$ may govern synthesis of essential components in the pathway. Taken together, all these observations point to an essential role for LXR $\alpha$ in cholesterol homeostasis. Because the effects of the knockout are most apparent under conditions of a high cholesterol diet, LXR $\alpha$ agonists might be effective in treatment of human disorders of cholesterol metabolism, especially those caused or exacerbated by dietary factors.

\section{The future of orphans}

The field of orphan receptors began with its first tenuous steps 10 years ago and has since made its impact felt in a number of important and fundamental ways. Not only has this pursuit led to the identification of new ligands and associated physiology but it has also brought in fresh ideas about physiologic and metabolic regulation. In the case of the most recently described receptors, several new concepts have emerged. For example, BXR provides not only a new class of receptor ligand (benzoates) but has disclosed an extremely early developmental signaling system. PXR and SXR have revealed new features of steroid metabolism and provide powerful evidence of a role for nuclear receptors in xenobiotic metabolism. CAR $\beta$ is the first example in which a ligand functions as a natural antagonist. Finally, the recent results with LXR $\alpha$ and PPAR $\gamma$ expand the role for orphan receptors in lipid metabolism and human disease.

Thus, orphan receptors not only contribute to our broader understanding of nuclear receptor signaling, but have provided new direction and insights at a breathtaking pace. With this progress in just the last year, we can only sit back and await what is undoubtedly to be a bountiful future harvest.

\section{Acknowledgments}

We thank Drs. Michael Downes, Barry Forman, and Peter Ordentlich for critical comments on the manuscript, and Barry Forman for communication of results before publication. This work was supported by National Institutes of Health grant GM26444 and the G. Harold and Leila Y. Mathers Charitable Foundation (R.M.E.). R.M.E. is an investigator of the Howard Hughes Medical Institute at the Salk Institute for Biological Studies.

\section{References}

Beato, M., P. Herrlich, and G. Schutz. 1995. Steroid hormone receptors: many actors in search of a plot. Cell 83: 851-857.

Blumberg, B., D.J. Mangelsdorf, J. Dyck, D.A. Bittner, R.M. Evans, and E.M. De Robertis. 1992. Multiple retinoid-responsive receptors in a single cell: families of RXRs and RARs in the Xenopus egg. Proc. Natl. Acad. Sci. 89: 23212325.

Blumberg, B., H. Kang, J. Bolado, Jr., H. Chen, A.G. Craig, T.A. Moreno, K. Umesono, T. Perlmann, E.M. De Robertis, and R.M. Evans. 1998a. BXR, an embryonic orphan nuclear receptor activated by a novel class of endogenous benzoate metabolites. Genes \& Dev. 12: 1269-1277.

Blumberg, B., W. Sabbagh, H. Juguilon, J. Bolado, Jr., E.S. Ong, and R.M. Evans. 1998b. SXR, a novel steroid and xenobioticsensing nuclear receptor. Genes \& Dev. (this issue).

Burger, H.-J., J.D. Schuetz, E.G. Schuetz, and P.S. Guzelian. 1992. Paradoxical transcriptional activation of rat liver cytochrome P-450 3A1 by dexamethasone and the antigluco- 
corticoid pregnenolone $16 \alpha$-carbonitrile: Analysis by transient transfection into primary monolayer cultures of adult rat hepatocytes. Proc. Natl. Acad. Sci. 89: 2145-2149.

Chawla, A., E.J. Schwarz, D.D. Dimaculangen, and M.A. Lazar. 1994. Peroxisome proliferator-activated receptor $\gamma$ : adiposepredominant expression and induction early in adipocyte differentiation. Endocrinology 135: 798-800.

Edwards, O.M., R.J. Courtenay-Evans, J.M. Galley, J. Hunter, and A.D. Tait. 1974. Changes in cortisol metabolism following rifampicin therapy. Lancet 2: 548-551.

Enmark, E. and J.A. Gustaffson. 1996. Orphan nuclear receptors-the first eight years. Mol. Endocrinol. 10: 1293-1307.

Forman, B.M., E. Goode, J. Chen, A.E. Oro, D.J. Bradley, T. Perlmann, D.J. Noonan, L.T. Burka, T. McMorris, W.W. Lamph, R.M. Evans, and C. Weinberger. 1995b. Identification of a nuclear receptor that is identified by farnesol metabolites. Cell 81: 687-693.

Forman, B.M., P. Tontonoz, J. Chen, R.P. Brun, B.M. Spiegelman, and R.M. Evans. 1995c. 15-deoxy- $\Delta^{12,14}$-prostaglandin J2 is a ligand for the adipocyte determination factor PPAR $\gamma$. Cell 83: 803-812.

Forman, B.M., K. Umesono, J. Chen, and R.M. Evans. 1995a. Unique response pathways are established by allosteric interactions among nuclear hormone receptors. Cell 81: 541550.

Forman, B.M., B. Ruan, J. Chen, G.J. Schroepfer, Jr., and R.M. Evans. 1997. The orphan receptor LXR $\alpha$ is positively and negatively regulated by distinct products of mevalonate metabolism. Proc. Natl. Acad. Sci. 94: 10588-10593.

Forman, B.M., I. Tzameli, H.-S. Choi, J. Chen, D. Simha, W. Seol, R.M. Evans, and D.D. Moore. 1998. Androstane metabolites bind to and deactivate the nuclear receptor CAR $\beta$. Nature (in press).

Giguere, V., N. Yang, P. Segui, and R.M. Evans. 1988. Identification of a new class of steroid hormone receptors. Nature 331: 91-94.

Gonzalez, F.J. 1992. Human cytochromes P450: Problems and prospects. Trends Pharmacol. Sci. 13: 346-352.

Gonzalez, F.J., B.-J. Song, and J.P. Hardwick. 1986. Pregnenolone 16a-carbonitrile-inducible P-450 gene family: gene conversion and differential regulation. Mol. Cell. Biol. 6: 2969-2976.

Janowski, B.A., P.J. Willy, T.R. Devi, J.A. Falch, and D.J. Mangelsdorf. 1996. An oxysterol signaling pathway mediated by the nuclear receptor LXR $\alpha$. Nature 383: 728-731.

Jiang, C., A.T. Ting, and B. Seed. 1998. PPAR- $\gamma$ agonists inhibit production of monocyte inflammatory cytokines. Nature 391: 82-86.

Kastner, P., M. Mark, and P. Chambon. 1995. Nonsteroid nuclear receptors: What are genetic studies telling us about their role in real life. Cell 83: 859-869.

Kliewer, S.A., K. Umesono, D.J. Noonam, R.A. Heyman, and R.M. Evans. 1992. Convergence of 9-cis retinoic acid and peroxisome proliferator signalling pathways through heterodimer formation of their receptors. Nature 358: 771-774.

Kliewer, S.A., J.M. Lenhard, T.M. Willson, I. Patel, D.C. Morris, and J.M. Lehmann. 1995. A prostaglandin J2 metabolite binds peroxisome proliferator-activated receptor $\gamma$ and promotes adipocyte differentiation. Cell 83: 813-819.

Kliewer, S.A., J.T. Moore, L. Wade, J.L. Staudinger, M.A. Jones, D.D. McKee, B.M. Oliver, T.M. Willson, R.H. Zetterstrom, T. Perlmann, and J. Lehmann. 1998. An orphan nuclear receptor activated by pregnanes defines a novel steroid signaling pathway. Cell 92: 73-82.

Kurokawa, R., J. DiRenzo, M. Boehm, J. Sugarman, B. Gloss, M.G. Rosenfeld, R.A. Heyman, and C.K. Glass. 1994. Regu- lation of retinoid signalling by receptor polarity and allosteric control of ligand binding. Nature 371: 528-531.

Kyriazopoulou, V. and A.G. Vagenakis. 1992. Abnormal overnight dexamethasone suppression test in subjects receiving rifampicin therapy. J. Clin. Endocrinol. Metab. 75: 315-317.

Kyriazopoulou, V., O. Parparousi, and A.G. Vagenakis. 1984. Rifampicin-induced adrenal crisis in Addisonian patients receiving corticosteroid replacement therapy. J. Clin. Endocrinol. Metab. 59: 1204-1206.

Lehmann, J.M., S.A. Kliewer, L.B. Moore, T.A. Smith-Oliver, B.B. Oliver, J.-L. Su, S.S. Sundseth, D.A. Winegar, D.E. Blanchard, T.A. Spencer, and T.M. Willson. 1997. Activation of the nuclear receptor LXR by oxysterols defines a new hormone response pathway. J. Biol. Chem. 272: 3137-3140.

Mangelsdorf, D.J. and R.M. Evans. 1995. The RXR heterodimers and orphan receptors. Cell 83: 841-850.

Mangelsdorf, D.J., C. Thummel, M. Beato, P. Herrlich, G. Schutz, K. Umesono, B. Blumberg, P. Kastner, M. Mark, P. Chambon, and R.M. Evans. 1995. The nuclear receptor superfamily: The second decade. Cell 83: 835-839.

Mueller, E., P. Sarraf, P. Tontonoz, R.M. Evans, K.J. Martin, M. Zhang, C. Fletcher, S. Singer, and B.M. Spiegelman. 1998. Terminal differentiation of human breast cancer through PPAR y. Mol. Cell 1: 465-470.

Mukherjee, F., P.J. Davies, D.L. Crombie, E.D. Bischoff, R.M. Cesario, L. Jow, L.G. Hamann, M.F. Boehm, C.E. Mondan, A.M. Nadzan, and R.A. Heyman. 1997. Sensitization of diabetic and obese mice to insulin by retinoid $\mathrm{X}$ receptor agonists. Nature 386: 407-410.

Nagy, L., P. Tontonoz, J.G.A. Alvarez, H. Chen, and R.M. Evans. 1998. Oxidized LDL regulates macrophage gene expression through ligand activation of PPAR $\gamma$. Cell 93: 229-240.

O'Malley, B. 1990. The steroid receptor superfamily: more excitement predicted for the future. Mol. Endocrinol. 4: 363369.

Peet, D.J., S.D. Turley, W. Ma, B.A. Janowski, J.-M.A. Lobaccaro, R.E. Hammer, and D.J. Mangelsdorf. 1998. Cholesterol and bile acid metabolism are impaired in mice lacking the nuclear oxysterol receptor LXR $\alpha$. Cell 93: 693-704.

Rendic, S. and F.J. Di Carlo. 1997. Human cytochrome P450 enzymes: a status report summarizing their reactions, substrates, inducers and inhibitors. Drug Metab. Rev. 29: 413580.

Ricote, M., A.C. Li, T.M. Willson, C.J. Kelly, and C.K. Glass. 1998. The peroxisome proliferator activated receptor- $\gamma$ is a negative regulator of macrophage activation. Nature 391: 79-82.

Schulman, I.G., C. Li, J.W.R. Schwabe, and R.M. Evans. 1997. The phantom ligand effect: allosteric control of transcription by the retinoid X receptor. Genes \& Dev. 11: 299-308.

Selye, H. 1971. Hormones and resistance. J. Pharm. Sci. 60: 128.

Smith, D.P., C.S. Mason, E.A. Jones, and R.W. Old. 1994. A novel nuclear receptor superfamily member in Xenopus that associates with RXR, and shares extensive sequence similarity to the mammalian vitamin D3 receptor. Nucleic Acids Res. 22: 66-71.

Spiegelman, B.M. 1998. PPAR $\gamma$ in monocytes: Less pain, any gain? Cell 93: 153-155.

Terzolo, M., G. Borretta, A. Ali, F. Cesario, G. Magro, A. Boccuzzi, G. Reimondo, and A. Angeli. 1995. Misdiagnosis of Cushing's syndrome in a patient receiving rifampicin therapy for tuberculosis. Horm. Metab. Res. 27: 148-150.

Tontonoz, P., E. Hu, and B.M. Spiegelman. 1994. Stimulation of adipogenesis in fibroblasts by PPAR $\gamma 2$, a lipid-activated transcription factor. Cell 79: 1147-1156. 
Tontonoz, P., L. Nagy, J.G.A. Alvarez, V.A. Thomazy, and R.M. Evans. 1998. PPAR $\gamma$ promotes monocyte/macrophage differentiation and uptake of oxidized LDL. Cell 93: 241-252.

Willy, P.J and D.J. Mangelsdorf. 1998. Nuclear orphan receptors: the search for novel ligands and signaling pathways. In Hormones and signaling (ed. B.W. O'Malley), Vol. 1, pp. 307358. Academic Press, San Diego, CA.

Willy, P.J., K. Umesono, E.S. Ong, R.M. Evans, R.A. Heyman, and D.J. Mangelsdorf. 1995. LXR, a nuclear receptor that defines a distinct retinoid-response pathway. Genes \& Dev. 9: $1033-1045$.

Zavacki, A.M., J.M. Lehmann, W. Seol, T.M. Willson, S.A. Kliewer, and D.D. Moore. 1997. Activation of the orphan receptor RIP14 by retinoids. Proc. Natl. Acad. Sci. 94: 79097914.

Zawawi, T.H., M.S. al-Hadramy, and S.M. Abdelwahab. 1996. The effects of therapy with rifampicin and isoniazid on basic investigations for Cushing's syndrome. Iran. J. Med. Sci. 165: 300-302. 


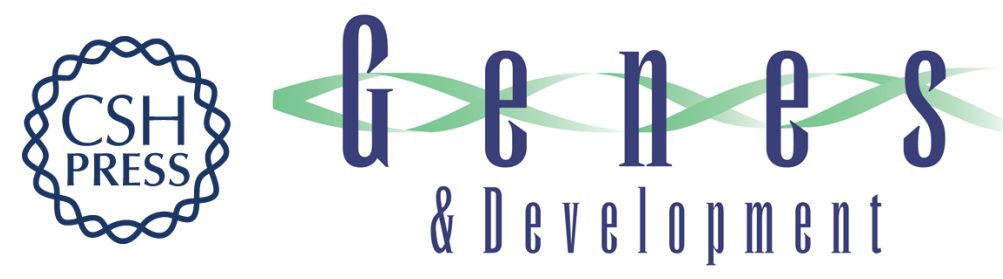

\section{Orphan nuclear receptors-new ligands and new possibilities}

Bruce Blumberg and Ronald M. Evans

Genes Dev. 1998, 12:

Access the most recent version at doi:10.1101/gad.12.20.3149

References This article cites 42 articles, 9 of which can be accessed free at: http://genesdev.cshlp.org/content/12/20/3149.full.html\#ref-list-1

License

Email Alerting Receive free email alerts when new articles cite this article - sign up in the box at the top Service right corner of the article or click here.

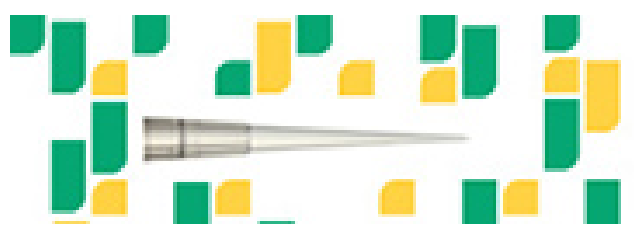

Focused on your science. 